\title{
The analysis of determining the value of the amplitude-frequency characteristics of the basic frame without spindle spinning $\left(\mathbf{R}_{1}\right.$ Rieterr)
}

\author{
Ph.D. Slobodan Stefanovic ${ }^{1}$, Ph.D. Radoje Cvejic ${ }^{2}$, Ph.D. Dusko Kostic ${ }^{3}$, Ph.D. \\ Radojko Lojanicic ${ }^{4}$, Ph.D. Dragoslav Ilic $^{5}$ \\ ${ }^{I}$ Professor, High School of Applied Professional Studies of Vranje, Serbia. \\ ${ }^{2,4}$ Professor, Faculty for strategic and operational management, Belgrade, Serbia \\ ${ }^{3}$ High Vocational School of Entrepreneurship, Belgrade, Serbia \\ ${ }^{5}$ JKP "Water" Zajecar, Serbia
}

\begin{abstract}
Based on the experimental values of mechanical oscillations at selected measuring points analyzed frame OE spinning machines, is determined by the correlation coefficient depending on the amplitude of the circular frequency, which is called the circular velocity in the plane of, depending on the amplitude of the oscillation frequency. Its numerical values are shown in this paper. This was necessary because no correlation coefficients is not possible to determine the frequency curves operational safety of the analyzed assembly $\mathrm{OE}$ spinning machines.
\end{abstract}

Keywords: - Without spindle spinning, amplitude - frequency characteristics circuit coil winding the finished yarn, OE spinning, the correlation coefficient.

\section{INTRODUCTION}

According to the spindle without a spinning process, the material is in the form of strips, the second passages to pull , through the opening roll, is introduced into the zone of action of the device for fiber thinning.

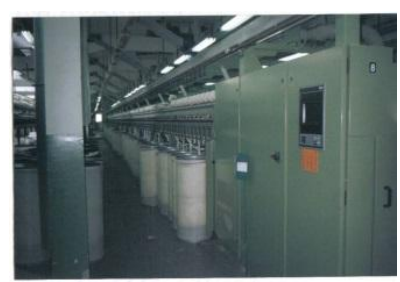

Figure 1. Displaying no spindle rotor spinning machines by Swiss company Rieterr denoted R1

Fiber thinning roller whose speed is $7000-8000(\mathrm{r} / \mathrm{min})$ is coated with a special garniture serrated so that the tape is pulled from the individual fibers, which is then by means of the air flow transported in the rotor for spinning. The separated individual fibers with the help of air flow entering tangentially to the wall of the rotor. Due to the high speed of the rotor (the rotor diameter of 32 and rotating speed $115000(\mathrm{r} / \mathrm{min})$ ) fiber is packed in the groove of the rotor in the form of a wedge parallel beam. Rotor due to centrifugal force and effect of Coriolis acceleration, ie. force, to form a certain shape of the yarn balloon. Yarn spun from the rotor through the drain rolls, is wrapped on the spool. Light leakage of yarn are in the range of $25-220(\mathrm{~m} / \mathrm{min})$, the capacity of the coil is to $5(\mathrm{~kg})$ with yarn wound on it (usually the capacity of the coil to $2(\mathrm{~kg})$ with wound yarn) [3]. Structural block diagram of winding yarn finished yarn at selected measuring points is shown in Figure 2.

\section{GENERAL ABOUT THE OCCURRENCE OF MECHANICAL OSCILLATIONS OF} THE ANAL YZED FRAME OF OE - SPINNING MACHINES

Mechanical oscillations of the component parts analyzed assemblies OE - spinning, forcibly arise and the consequences of the action of dynamic forces within the system to change its direction and intensity (size). Identification of their origin is based on the concept of deterministic occurrence of dynamic forces. When analyzed OE - spinning each source generates mechanical vibrations. The most common reasons that cause mechanical oscillations (vibrations) in components and components analyzed OE - spinning are [4]: 


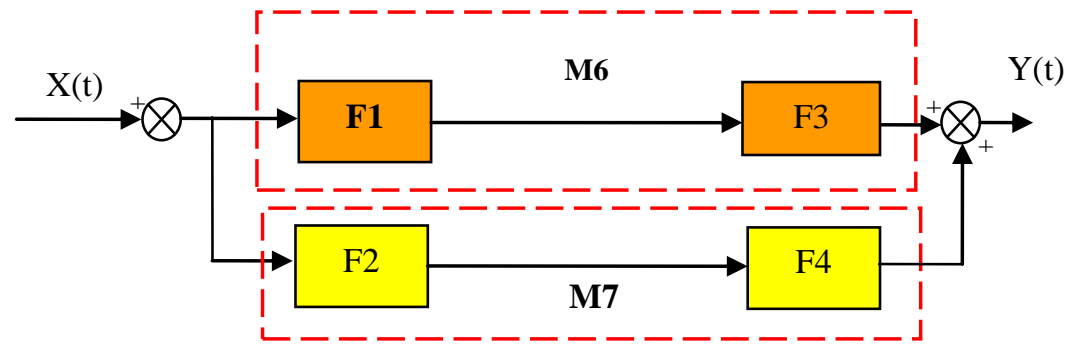

Figure 2. Displaying assembly for winding coils finished yarn through structural blocks [7].

Where: M6 - measurement point level fluctuations on the thread guide and the reel coils to rotate in its winding the finished yarn, M7 - measurement point level fluctuations tensioner/riser coils, and the coils holder.

1. Unbalance rotating parts (rotary parts);

2. Insufficient dynamic stiffness of the chassis and its support (light foundation);

3. Malfunction roller bearings;

4. Wear of components and components for the appearance of friction (turbo - mechanical processes);

5. Turbulent flow and accumulation of contaminants in the processing of yarn (the appearance of wear and tear due to friction in the intakes of the box);

6. Wear of the teeth (furniture razvlakivanje) rotating elements and components;

7. The effect of electromagnetic forces that affect the proper operation of electrical and electronic components;

8. Cancellations elastic (spring) components due to the appearance of their elongation;

9. Looseness in the joints.

Based on the above mentioned reasons that cause mechanical oscillations (vibrations) for elements and components analyzed $\mathrm{OE}$ - spinning made the divisions of their influence on the part of boxing and spinning within the coil winding the finished yarn (Figure 3) [2].

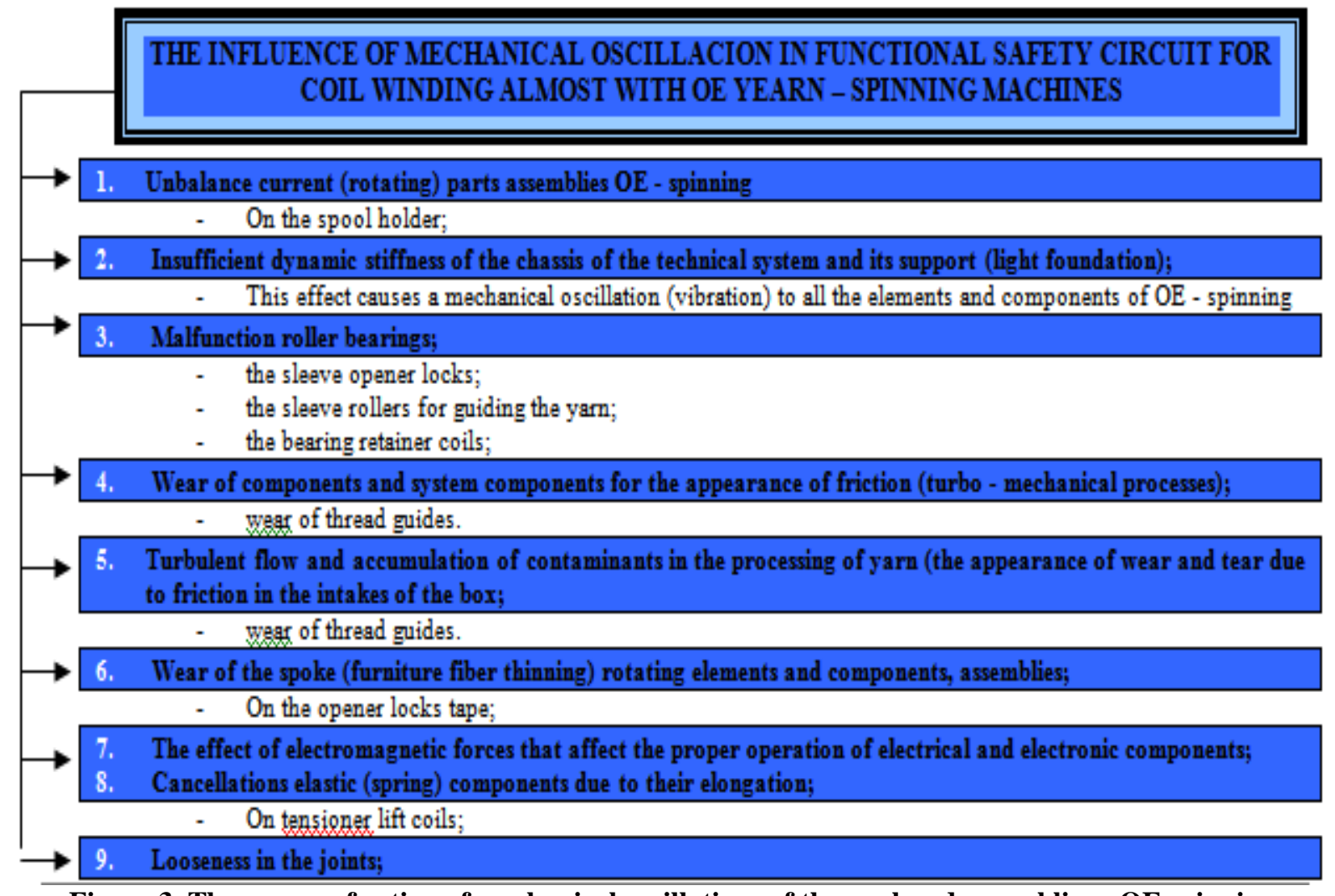

Figure 3. The course of action of mechanical oscillations of the analyzed assemblies - OE spinning machines 
The analysis of determining the value of the amplitude-frequency characteristics of the basic frame

\section{EXPERIMENTAL ANALYSIS OF OBTAINING OSCILLATION AREA FOR EACH} UNIT INTEGRAL COMPONENT OF THE ANALYZED FRAME

Experimental analysis shows the three stages of studying the basics of mechanical oscillations at selected measuring points and included :

1. Global knowledge of the process of oscillation;

2. The experiment for measuring the mechanical oscillations;

3. The results obtained identification (analysis).

1. Global knowledge of the process of oscillation (choice of measurement points on which they had level measurement of mechanical oscillations)

Measurements of mechanical oscillations are comprised of two selected sampling points whose position is shown graphically in Figure 1. and are located in the following places;

VI measurement point: located in the lower part of the lever lift mechanism pickup coils;

VII measurement point: located on opposite sides of the bracket and the coil to the top of the lift mechanism lever pickup coils.

The choice of the location of the measuring points is selected for the following reasons:

- measurement point VI, was chosen to be the location of the control values of mechanical oscillations (vibrations) that occur in a straight line - oscillatory motion thread guide, and a circular motion to rotate the cylinder coil on coil winding the finished yarn. This roller and tapered roller on which the yarn is wound over the pair.

- measurement point VII, was selected to be on this site can be measured by the value of the mechanical oscillations that occur when working spool holder (plastic insert a bracket that is hooked on anti-friction bearings, all of which rely on the upper lever lift mechanism for lifting coils).

\section{The experiment for measuring the mechanical oscillation}

Measurement of mechanical oscillations (vibrations) at selected measuring points (as explained in the previous section) was performed following measuring equipment that constitutes the measuring chain:

1. A device for the measurement of mechanical oscillations (vibrations), data collector denoted 2526 MK2;

2. Accelerometer denoted 4391;

3. A software package for data processing, software program SENTINEL.

This equipment is the latest generation of test equipment used to obtain the values of mechanical oscillations (vibrations).

The experiment consisted of the following combinations of measuring the level of mechanical oscillations of the structural components of the built-in circuit spinning and boxing circuit for the coil winding the finished yarn. These combinations with the goal to obtain as precise measurement results of mechanical oscillations (vibrations). The order in which the measurements are included the following combinations of the constituent components of the circuits are:

Measurement I. Includes measuring the level of mechanical oscillations when the assemblies installed all new components;

Measurement II. Includes measuring the level of mechanical oscillations in circuits when they are built right components and are in operation.

Measurement III. Includes measuring the level of mechanical oscillations when the built-in circuits worn components (except beds and cartridge holder grafts taken as new otherwise would not be able to perform the measurement, because this is the ultimate place where the process ends, and could not to make winding the yarn on the spool as the final stage of spinning).

Measurement IV. Includes control (repeat) measurement, measurement III (repeated due to more sophisticated levels of oscillation that. Belts amplitude and frequency).

\section{Identification of the results (analysis)}

Measuring control of mechanical oscillations, ie. measuring the size of the parameter of random (stochastic random function) in the selected control points, were performed views in the spatial system $O X Y Z$, where the $O X$ - axis shows the value of the frequency function of the amplitude $(A(f))$, the $O Y$ - axis oscillation of the time $(t)$ while in $O Z$ - axis shows the value of the amplitude of oscillation. These values in the spatial system are shown for each signal at the measuring point and the sequence of measurements. This display mode for the sequence of measurement is most useful because it gives a true picture of the level of the oscillation spectrum and on the basis of their value determines the value of the belt depending on the amplitude of the oscillation frequency.

As the dependence of the amplitude of oscillation as a function of time ( $t$ ) that is non-periodic size. it is random (stochastic) values, which are concluded from the presented spectra of oscillation, it is necessary to 
carry out their analysis of decomposition of this spectrum (random function $A(t)$ ) of the sum of harmonic components on the basis of which determine the frequency spectrum of oscillations (as shown in Figures 5 to 11), which showed an example of measurements of amplitude - frequency characteristics of the measuring points of the analyzed assemblies.

Based on the graphic display (diagram) oscillating random (stochastic) function can be determined by the value of the level of oscillation (amplitude and frequency) for each component of the components of assemblies. These values are presented The results obtained by measuring the oscillation part of a belt (band portion includes max., And min. Values of amplitude and frequency) in-order measurement, while their mean values are determined by spectral analysis of random functions and based on the stochastic parameters describing the random function.

\section{FREQUENCY SPECTRUM MEASURED VALUES OF OSCILLATING INTEGRAL COMPONENTS OF THE ANALYZED ASSEMBLIES FOR RESPECTIVELY MEASUREMENTS PERFORMED ON CONCRETE EXAMPLES}

The frequency of oscillation spectra are selected so that each band represents the stilling of the component assembly ie. response, and are shown in the diagrams of oscillation $A=f(f)$, for measurements performed with respect to each measurement point (at the example of measurements of amplitude - frequency characteristics of the measuring points analyzed assemblies).

The obtained diagrams that were created from the data processing of measurements, certain sizes of extreme values (max. and min.) amplitude and frequency. Reviews are carried out in sequence diagrams and charts with each oscillation. Experimentally obtained values will be used in the analysis of correlation and, depending on the parameters linking the reliability of the components and assembly of mechanical oscillations influence on their work. Also, these values will be used in determining the stability (analysis allowed the work to the risk) of each measuring point, ie. each structural component of the analyzed assemblies [3] ..

In addition, it will be shown an example of the measurements of amplitude - frequency characteristics of the measuring points of the analyzed assemblies. On the basis of determining the extreme values depending $\left(A_{i}, f_{i}, \omega_{i}\right)$ on which will be used to determine the circular velocity dependence of the amplitude of oscillation frequencies.

Based on the above measurement procedure can be experimentally determined coefficients depending on the level of amplitude and frequency as important parameters in the analysis of the safety function.

Based on the experimental data, determine the amplitude and correlation coefficients for each band in a component of the analyzed assemblies.

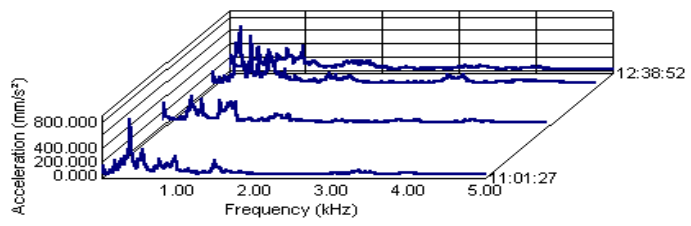

Machine: Section 1 Point: Measuring point

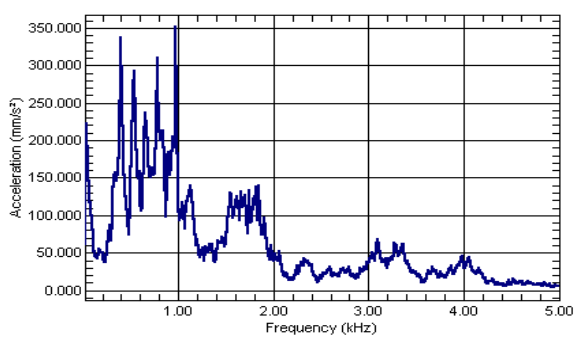

Machine: Section 1 Point: Measuring point 7,

Figure 4. Spatial and planar view of oscillation of measurement point 6

The procedure of collecting the experimental data shown in the diagram in the space and a plane system as an example of the measurements at regular intervals (as shown in Figures 4 and 5).

Machine: Section 1 Point: Measuring point 7,

Machine: Section 1 Point: Measuring point 7, 

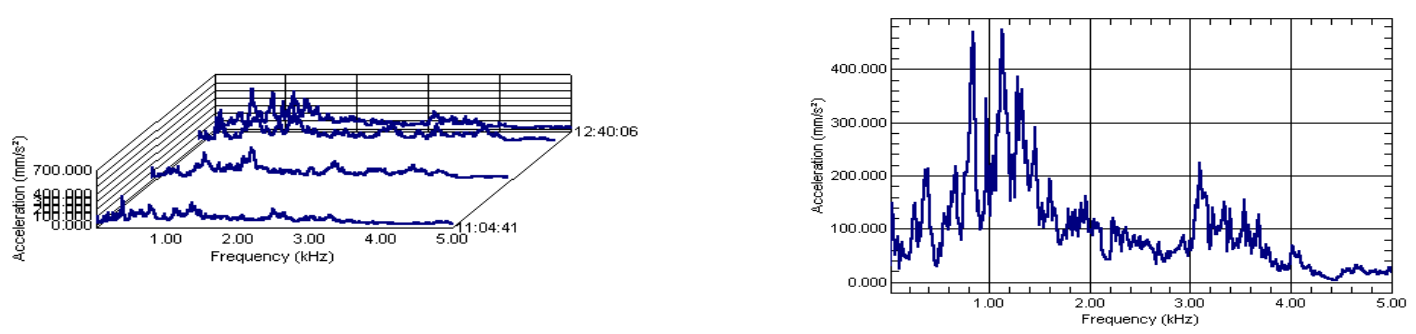

Figure 5. Spatial and planar view of oscillation of measurement point 7

Based on the graphic display (diagram) oscillating random (stochastic) function can be determined by the value of the level of oscillation (amplitude and frequency) for each component of the components of assemblies.

These values are presented The results obtained by measuring the oscillation part of an area (area portion includes max.and min. Values of amplitude and frequency) in-order measurement, while their mean values are determined by spectral analysis of random functions and based on the stochastic parameters describing the random function (tables 1, 2, - NUMERIC VALUES EXTREMES (VALUE PEAKS OSCILLATION AMPLITUDE) STOCHASTIC SIZE FROM THE DIAGRAMS SHOWN AMPLITUDE - FREQUENCY CHARACTERISTICS) [2].

Table 1. Extreme value fluctuations at the measuring point 6 - Measuring point 6 . Areas of analysis included the value of the frequency spectrum in the range of oscillation $f 6(A 6(t))=0.0375 \div 2.1625$.

\begin{tabular}{|c|c|c|c|c|}
\hline $\begin{array}{c}\text { Ordina } \\
\mathbf{I}\end{array}$ & $\begin{array}{c}\text { The } \\
\text { frequency } \\
\text { of } \\
\text { oscillation } \\
\mathbf{F}_{2}[\mathbf{k H z}]\end{array}$ & $\begin{array}{c}\text { The } \\
\text { amplitude of } \\
\text { the oscillation } \\
\mathbf{A}_{7}\left[\mathbf{m} / \mathbf{s}^{2}\right]\end{array}$ & \multicolumn{2}{|c|}{$\begin{array}{c}\text { The experimental } \\
\text { value } \\
\text { max. } \\
\text { min. }\end{array}$} \\
\hline 1. & 0.0375 & 0.147347 & $\sqrt{ }$ & \\
\hline 2. & 0.1125 & 0.0255573 min & & $\sqrt{ }$ \\
\hline 3. & 0.2625 & 0.147347 & $\sqrt{ }$ & \\
\hline 4. & 0.2875 & 0.0660828 & & $\sqrt{ }$ \\
\hline 5. & 0.3625 & 0.211645 & $\sqrt{ }$ & \\
\hline 6. & 0.475 & 0.0298601 & & $\sqrt{ }$ \\
\hline 7. & 0.6625 & 0.216497 & $\sqrt{ }$ & \\
\hline 8. & 0.725 & 0.0801508 & & $\sqrt{ }$ \\
\hline 9. & 0.8375 & 0.470911 & $\sqrt{ }$ & \\
\hline 10. & 0.9125 & 0.0977587 & & $\sqrt{ }$ \\
\hline 11. & 0.975 & 0.345489 & $\sqrt{ }$ & \\
\hline 12. & 1.0125 & 0.124613 & & $\sqrt{ }$ \\
\hline 13. & 1.125 & 0.473413 max & $\sqrt{ }$ & \\
\hline 14. & 1.2125 & 0.152163 & & $\sqrt{ }$ \\
\hline 15. & 1.2875 & 0.3855313 & $\sqrt{ }$ & \\
\hline 16. & 1.4 & 0.172066 & & $\sqrt{ }$ \\
\hline 17. & 1.4625 & 0.290316 & $\sqrt{ }$ & \\
\hline 18. & 1.5875 & 0.122935 & & $\sqrt{ }$ \\
\hline 19. & 1.6 & 0.194068 & $\sqrt{ }$ & \\
\hline 20. & 1.7 & 0.0713927 & & $\sqrt{ }$ \\
\hline 21. & 1.9625 & 0.160225 & $\sqrt{ }$ & \\
\hline 22. & 2.175 & 0.0424938 & & $\sqrt{ }$ \\
\hline
\end{tabular}


The analysis of determining the value of the amplitude-frequency characteristics of the basic frame

Table 2. Extreme value fluctuations at the measuring point 7 - Measuring point 7. Areas of analysis included the value of the frequency spectrum in the range of oscillation $\mathrm{f} 7(\mathrm{~A} 7 \mathrm{t}))=0.0375 \div 2.175[\mathrm{kHz}]$

\begin{tabular}{|c|c|c|c|c|}
\hline Ord-inal & $\begin{array}{c}\text { The frequency of oscillation } \\
\mathbf{F}_{\mathbf{2}}[\mathbf{k H z}]\end{array}$ & $\begin{array}{c}\text { The amplitude of the oscillation } \\
\mathbf{A}_{\mathbf{6}}\left[\mathbf{m} / \mathbf{s}^{\mathbf{2}}\right]\end{array}$ & $\begin{array}{c}\text { The experimental value } \\
\text { max. }\end{array}$ \\
\hline 1. & 0.0375 & 0.222906 & $\sqrt{ }$ & \\
\hline 2. & 0.15 & 0.0431347 & & $\sqrt{ }$ \\
\hline 3. & 0.4 & 0.337708 & $\sqrt{ }$ & $\sqrt{ }$ \\
\hline 4. & 0.475 & 0.0746274 & $\sqrt{ }$ & $\sqrt{ }$ \\
\hline 5. & 0.5375 & 0.292299 & $\sqrt{ }$ & \\
\hline 6. & 0.6125 & 0.105754 & & $\sqrt{ }$ \\
\hline 7. & 0.65 & 0.237462 & & $\sqrt{ }$ \\
\hline 8. & 0.7125 & 0.15046 & $\sqrt{ }$ & \\
\hline 9. & 0.775 & 0.310457 & & $\sqrt{ }$ \\
\hline 10. & 0.8625 & 0.0981248 & $\sqrt{ }$ & \\
\hline 11. & 0.975 & 0.350707 max. & & $\sqrt{ }$ \\
\hline 12. & 1.0625 & 0.0821038 & & $\sqrt{ }$ \\
\hline 13. & 1.125 & 0.139169 & & $\sqrt{ }$ \\
\hline 14. & 1.225 & 0.0441112 & & $\sqrt{ }$ \\
\hline 15. & 1.85 & 0.139749 & & \\
\hline 16. & 2.1625 & 0.0138086 max. & & \\
\hline
\end{tabular}

\section{DETERMINING THE VALUE OF THE OSCILLATION FREQUENCY TO THE DISPLAYED (REFERENCE) EXAMPLE OF MEASUREMENTS AMPLITUDE - FREQUENCY CHARACTERISTICS AT SELECTED MEASURING POINTS OF THE ANALYZED ASSEMBLIES}

Determination of dependence (correlation) oscillation frequency as a function of oscillation amplitude $f_{i}=A_{i}\left(f_{i}\right)$, is determined on the basis of the recorded spectra of stochastic (random) oscillatory signal. The values of these signals are displayed numerically (iterative) values, obtained by the extreme values (peak signal) oscillatory stochastic processes. The observed spectra include the extent to calming works stochastic signal is determined as the arithmetic mean of the extreme values of stochastic signals [1].

Analysis to determine the correlation depending on the frequency of the oscillation amplitude as a function of oscillation $f_{i}=A_{i}\left(f_{i}\right)$, started from their values obtained by means of a software package for processing data SENTINEL. This software package has been provided all the numerical values of all points measured values presented stochastic signal to a selected reference example.

Shows an example of the measured signal is the reference for the reason because it was created by measuring the same after the completion of the overhaul OE - spinning. Also, it is important for the measurement carried out on spinning box no. 1, which is located immediately after the driveline OE - spinning, so it's most burdened in terms of the influence of mechanical oscillations in his work.

Radian frequency, depending on the frequency of oscillation of the measuring points analyzed circuits, $\omega_{i}=f\left(f_{i}\right)$, can be expressed via a standard physical expression [6]:

$$
\omega_{i}=2 \cdot \pi \cdot f_{i},
$$

wherein: the coefficient of the angle in the plane $2 \cdot \pi=$ const., so that their dependence is linear, ie. the value of the circular frequency is increased by the product of the constant coefficient $2 \cdot \pi$.

To determine the circular frequency at selected measuring points $\left(\omega_{1}, \omega_{2}, \omega_{3}, \omega_{4}, \omega_{5}, \omega_{6}, \omega_{7}\right)$ will go to the numeric values depending on the amplitude - frequency characteristics (their values are shown in tables in the appendix). The analysis of the model will take two characteristic values, ie. extreme values of circular frequencies $\left(\omega_{i \text { max }}, \omega_{i \text { min. }}\right)$ that are dependent on extreme values amplitude oscillation $\left(A_{i \text { max. }}, A_{i \text { min. }}\right)$. View these characteristic values are found in Table 3. 
Table 3. The extreme values $\left(A_{i}, f_{i}, \omega_{i}\right)$ of the analyzed characteristic examples

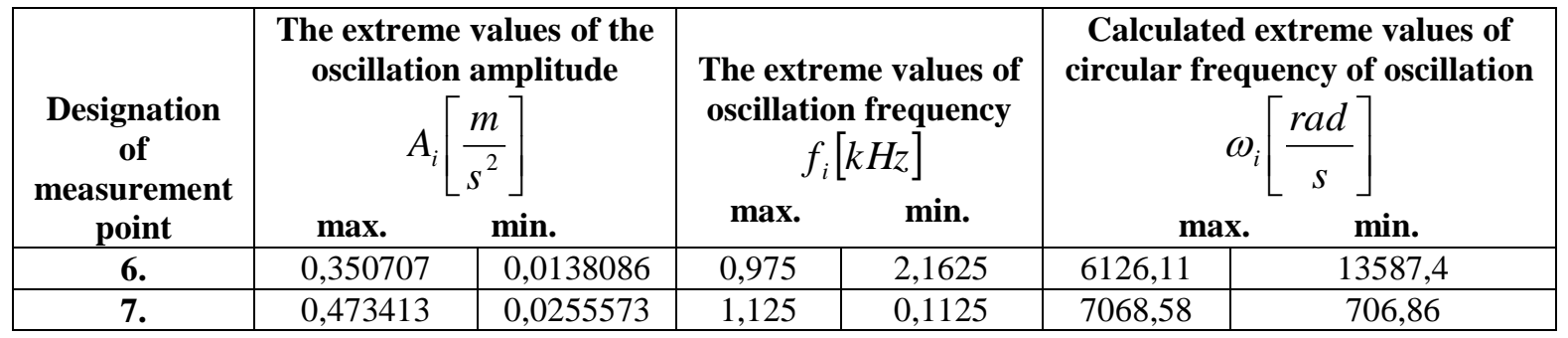

Based on these extreme numerical values depending on the amplitude and circular frequency of oscillation can be determined by the correlation coefficients of the form:

$$
\lambda_{i}(\max , \min )=\frac{A_{i}(\max ., \min )}{\omega_{i}(\max ., \min )}\left[\frac{\mathrm{m}}{\mathrm{rad} \cdot \mathrm{s}}\right],
$$

we will call them angular velocity in the plane, depending on the amplitude of the oscillation frequency, where: $i$ - the number point recorded of measurement results oscillation $i=1,2,3,4,5,6,7$.

The values obtained correlation coefficients are presented in tables (Table 4.).

Table 4. The values of correlation coefficients

\begin{tabular}{|c|c|c|}
\hline $\begin{array}{c}\text { Designation of } \\
\text { measurement } \\
\text { point }\end{array}$ & \multicolumn{2}{|c|}{ Correlation coefficients } \\
$\lambda_{\max .}$ & $\lambda_{\text {min. }}$ \\
\hline $\mathbf{6 .}$ & $5,725 \cdot 10^{-4}$ & $1,016 \cdot 10^{-6}$ \\
\hline $\mathbf{7 .}$ & $6,697 \cdot 10^{-4}$ & $3,616 \cdot 10^{-5}$ \\
\hline
\end{tabular}

Based on the value of the correlation coefficient (Figure 5.) shows the curve depending on the frequency of safety of of the exploitation operation time integral component assembly for winding coils the finished yarn for optimum security model. Optimal security model includes the value of work components with acceptable risk. Shown on figure 5. clearly evident band is absolutely safe operation of the analyzed circuit and it lies between the values shown depending on fault $M_{\xi}(t)_{N K}=f(t)$. [2]

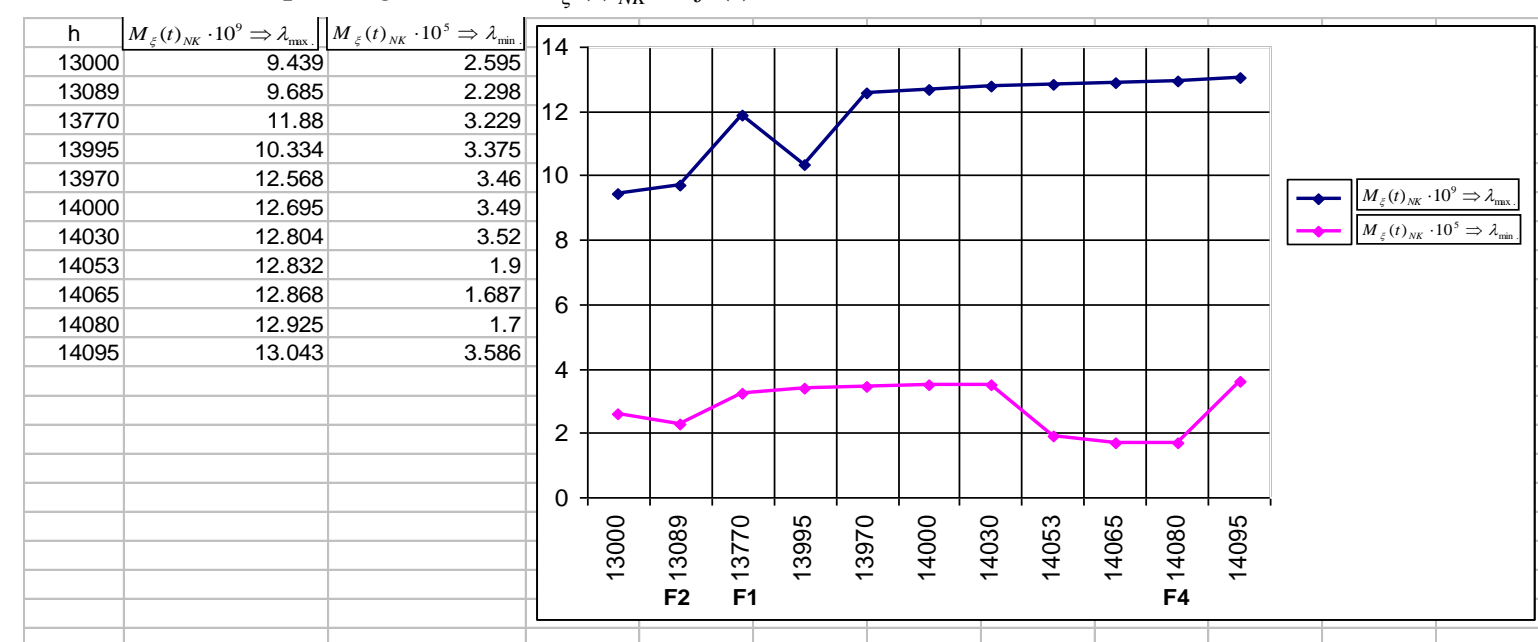

Figure 5. Diagram of frequency of security depending on the exploitation operation time integral component assembly for winding coils the finished yarn on which technologies are implemented procedures for preventive maintenance - optimal model

\section{CONCLUSION}

In the first part of this paper an experimental analysis included the character of phenomena influence the mechanical oscillations of the analyzed within OE - spinning. The above are the most common causes 
resulting from increasing levels of mechanical oscillations. Ranked by of impact of failure which lead to this phenomenon. On the basis of these data flow is executed action of mechanical oscillations of the analyzed circuit OE - spinning. Also in this part of the analysis is explained and the character of the mechanical oscillation of the control measurement points.

The second part presents experimental analysis to obtain the area oscillation for each component of the analyzed component assembly. This included the location of the selected measurement locations where measurements were performed mechanical oscillations, as well as the necessary explanations on the selection of the location of the measuring points, the choice of equipment which is carried out in an experimental analysis of measurement chain, and the sequence of measurements.

The third part explains the identification of the results recorded by the diagram in physical systems $O X Y Z$ that are displayed depending amlituda oscillation frequency of the oscillation. These curves are shown in a plane system. The procedure of collecting experimental data is shown in the reference example. On it are certain values of oscillation frequencies.

\section{REFERENCES}

[1] S. Stefanović, Reserch Into The Causes Of Inaccuracies Of Components Of Complex For Coil Winding With Finished Yern At Oe., Lucrarea Trimisă Redacţiei Metalurgia International A Fost Acceptată Spre Publicare În Numărul 2013., Issn 1582 - 2214, “Metalurgia International” Is Introduced In Thomson Scientific Master Journal List, Letter M, Position 440. Vol. 18 Special Issue No. 8, Str. 96 - 101 (2013).

[2] S. Stefanovic, The Analysis Of Functioning Of Basic Components Of Oe - Technical System, International Journal Of Engineering, Tome Xi (Year 2013). Fascicule 1. Str. 237-244, Issn 1584 - 2665 , Annals Of Faculty Engineering Hunedoara, Romania.

[3] S. Stefanovic, Determination Of The Value Of Selected Oscillation Frequency Measurement Point Analyzed Parts Oe Spinning - On The Box Spinning, Priyanka Research Journal Publication, International Journal Of Mechanical Engineering Research And Development (Ijmerd) Issn 22489347, India, (2012). Journal Impact Factor (2011) - 0.9278 Calculated By Gisi.

[4] S. Stefanovic, Determination Operation Time Risk Of Box Spinning Components - Oe Spinning Machine, American Journal Of Engineering Research (Ajer) Issn : 2320-0847, Volume-Xx, Issue-4, (2013).

[5] S. Stefanovic, R. Cvejic, D. Kostic, S. Radivojevic, I. Kriss, Forming Of Universal Optimal Operation Model Of Frame For Coil Winding With Finished Yarn According To Selected Measuring Points Based On The Effect Of Mechanical Oscillations, American Journal Of Engineering Research (Ajer) Issn : 2320-0847, Volume-Xx, Issue-10, (2013).

[6] S. Stefanovic, R. Cvejic, R. Lojanicic, D. Kostic, Reserch Into The Causes Of Inaccuracies Of Components Of Complex For Coil Winding With Finished Yern At Oe, Paper 2., Page 16 - 26. , Inetarnational Journal Of Process Management - New Technoologies (Jpmnt) Issn: 2334-7449, Volume 1 Issue 4, October, 2013.

[7] S. Stefanovic, Uticaj Pojava Maheničkih Oscilacija Na Sigurnost Funkcionisanja Sklopova U Sistemu Prenosa Snage Tekstilnih Mašina, Univerzitet U Novom Sadu, Srbija, 2006.

[8] S. Stefanović, Opšti Uzročnici Nastajanja Mehaničkih Vibracija Kod Tehničkih Sistema U Tekstilnoj Industriji, Časopis Omo Br.7-8/2001., Str. 368 - 372, Beograd. , Issn 0350 - 1647.

[9] S. Stefanovic, Diagnosis Of State In Determining The Value Of Frequency Unit Winding Yarns Oe Spinning Machines, Naučno - Stručni Časopis „,Tehnička Dijagnostika“, Godina Xii, Br. 2, Str. 34 - 44, 2013. Issn 1451-1975.

[10] S. Stefanović, Formiranje Univerzalnog Optimalnog Modela Sigurnosti Funkcionisanja Sistema Za Namotavanje Prediva, Naučno - Stručni Časopis „Održavanje Mašina“, Br. 9-10, Str. 17-24, Smederevo, 2008, Issn 1452 - 9688. 